\title{
A CONTRIBUIÇÃO DO MODELO SOCIAL DA DEFICIÊNCIA PARA A COMPREENSÃO DO TRANSTORNO DO ESPECTRO AUTISTA
}

\section{THE CONTRIBUTION OF THE SOCIAL MODEL OF DISABILITY TO UNDERSTANDING AUTISTIC SPECTRUM DISORDER}

\author{
DOI: http://dx.doi.org/10.5965/1984317815022019187 \\ Solange Cristina da Silva \\ Universidade do Estado de Santa Catarina \\ profsolangeudesc@gmail.com \\ Marivete Gesser \\ Universidade Federal de Santa Catarina \\ mariveteg@gmail.com \\ Adriano Henrique Nuernberg \\ Universidade Federal de Santa Catarina \\ adrianoh@cfh.ufsc.br
}

\begin{abstract}
RESUMO
O objetivo deste artigo é o de identificar contribuições do modelo social da deficiência para a compreensão do Transtorno do Espectro Autista, considerado, hoje, no Brasil, uma condição de deficiência. $\mathrm{O}$ estudo se caracterizou como uma pesquisa de cunho bibliográfico e de caráter conceitual. Para tanto, utilizou-se principalmente de referências da área da Educação, Psicologia e Sociologia que permitiram fomentar o debate sobre a compreensão do autismo. Os resultados do estudo apontaram que o modelo social da deficiência pode contribuir significativamente para repensar o conceito de deficiência e as práticas voltadas a essa população em várias áreas como Arte, Educação, Psicologia, dentre outras. $O$ entendimento da deficiência como uma variação humana, o questionamento acerca dos processos de normatização e homogeneização vivenciados pelas pessoas com deficiência, a ênfase na singularidade e interseccionalidade dessa experiência e a defesa do direito de participação em igualdade de condições são alguns pontos de destaque.
\end{abstract}

Palavras-chave: Modelo Social da Deficiência. Transtorno do Espectro Autista. Estudos sobre Deficiência. Educação Especial

\section{ABSTRACT}

The objective of this article is to identify the contributions from the social model of disability to understanding autism, which, in Brazil, is presently considered a disability. The study was characterized as a bibliographic research of conceptual character. Therefore, is used mainly references from the fields of Education, Psychology and Sociology, which allowed instigate the discussion about autism comprehension. The results of the study indicated that the social model of disability can contribute significantly to rethink the concept of disability and the practices aimed at this population in different areas such as Art, Education, Psychology, among others. The understanding of disability as a human variation, the questioning about the standardization processes and homogenization experienced by people with disabilities, the emphasis on singularity and intersectionality of this experience and the defense of the right of equal conditions of participation are some highlights.

Keywords: Social Model of Disability. Autism Spectrum Disorder. Disability Studies. Special Education. 


\section{INTRODUÇÃO}

O autismo ${ }^{1}$ é caracterizado, do ponto de vista biomédico, como um transtorno do desenvolvimento com causas neurobiológicas (APA - AMERICAN PSYCHIATRIC ASSOCIATION, 2014). A partir da aprovação da Lei no 12.764/2012 - Política Nacional de Proteção dos Direitos da Pessoa com Transtorno do Espectro Autista, as pessoas com Transtorno do Espectro Autista (TEA) foram consideradas pessoas com deficiência (BRASIL, 2012). Há diferentes modelos de compreensão da deficiência, os quais oferecem diferentes pressupostos teórico-metodológicos para a compreensão do autismo. Neste artigo, abordar-se-á o modelo social da deficiência.

Ao considerar esses aspectos da construção social no autismo, buscou-se discutir sobre a contribuição do modelo social da deficiência para sua compreensão. Para tanto, optou-se pela pesquisa bibliográfica, de artigos científicos e livros nacionais e internacionais, de diversos autores que abordam o tema em diferentes áreas do conhecimento. A pesquisa bibliográfica, de acordo com Gil (2002, p. 45), "se utiliza fundamentalmente das contribuições dos diversos autores sobre determinado assunto". Gil (2008) argumenta que a escolha do problema de pesquisa abarca várias implicações, dentre elas algum tipo de comprometimento, e sugere que o problema seja elaborado em forma de pergunta. Nesse sentido, a questão principal desta pesquisa é: qual a contribuição do modelo social da deficiência para a compreensão do Transtorno do Espectro Autista?

Para responder a essa pergunta de pesquisa, serão realizadas a conceitualização do Transtorno do Espectro Autista (TEA) e a do modelo social da deficiência e, por último, serão apresentadas algumas contribuições deste modelo para a compreensão do autismo.

\section{MODELO SOCIAL DA DEFICIÊNCIA E SUA CONTRIBUIÇÃO PARA A COMPREENSÃO DO AUTISMO}

O Transtorno do Espectro Autista, de acordo com o Manual de Diagnóstico Estatístico de Transtornos Mentais - DSM-5, é caracterizado por uma condição neurodesenvolvimental com prejuízos persistentes na comunicação e interação

\footnotetext{
${ }^{1}$ Neste artigo, "autismo" será usado como sinônimo de Transtorno do Espectro Autista (termo este descrito no DSM-5).
} 
social em contextos diversos, além de interesses restritos e comportamentos repetitivos. Esse transtorno, por sua variabilidade nas dificuldades apresentadas, exigindo maior ou menor apoio, é classificado por níveis de severidade - nível 1, 2 ou 3 descritos no DSM-5. (APA, 2014). Hughes (2015, p. 2. Tradução nossa) informa que "o autismo é caracterizado como uma desordem do espectro porque os sintomas ocorrem em vários contextos e podem variar significativamente em termos de quão pronunciados são"2.

De acordo com o DSM-5, o TEA "engloba transtornos antes chamados de autismo infantil precoce, autismo infantil, autismo de Kanner, autismo de alto funcionamento, autismo atípico, transtorno global do desenvolvimento sem outra especificação, transtorno desintegrativo da infância e transtorno de Asperger" (APA, 2014, p. 53). Entendeu-se que esses transtornos são de uma mesma condição com gradações diferentes e a subclassificação dificultaria o diagnóstico, por isso ficaram todos incluídos num único diagnóstico - o Transtorno do Espectro Autista (ARAÚJO; NETO, 2014).

Alinhada ao DSM-5, a Classificação Internacional de Doenças (CID) International Classification of Diseases (ICD) -, na sua $11^{\text {a }}$ revisão, definido como CID 11, unificou os diagnósticos com código iniciado com F84 (Autismo Infantil F84.0, Autismo Atípico - F84.1, Síndrome de Rett - F84.2, Transtorno Desintegrativo da Infância - F84.3, Transtorno com Hipercinesia Associada a Retardo Mental e a Movimentos Estereotipados - F84.4, Síndrome de Asperger - F84.5, Outros TGD F84.8 e TGD sem Outra Especificação - F84.9). Esses diagnósticos anteriormente ficavam dentro dos Transtornos Globais do Desenvolvimento e atualmente compõem o Transtorno do Espectro Autista com o código 6A02. Eliminou-se, também, as subcategorias e níveis de classificação, tipificando apenas em relação a prejuízos na linguagem funcional e deficiência intelectual (WORLD HEALTH ORGANIZATION, 2018; TISMOO, 2018).

Nessa perspectiva, esse manual da Psiquiatria, como outros documentos da área da saúde, tem como base o modelo médico. Esse modelo, também denominado modelo individual, reforça a deficiência como inerente ao campo das doenças ou suas consequências, colocando a pessoa com deficiência no lugar de

\footnotetext{
2 Cf. o trecho original: "Autism is characterized as a spectrum disorder because symptoms occur across multiple contexts and can vary significantly in terms of how pronounced they are".
} 
doentes e inválidos. Assim, "o foco é na anormalidade do corpo", o qual "passa a ser patologizado" (PEREIRA, 2008, p. 32). Tendo como base esses aspectos para a compreensão do Transtorno do Espectro Autista, este também se torna patologizado. Dentro dessa lógica, "o autismo é frequentemente visto como um problema médico, o que significa que os cientistas tentam entender o autismo principalmente em termos de como o cérebro das pessoas funciona"3 (O'DELL et al., 2016, p. 166. Tradução nossa), medindo assim o seu desvio em relação ao cérebro neurotípico. Ao ter clareza sobre como funciona o cérebro, aumentam as chances de se construírem formas de corrigi-lo, adequá-lo ao padrão de normalidade.

Gabel e Connor (2008) afirmam que o modelo médico, ao propor tratar as pessoas com deficiência e as intervenções políticas com base em seus princípios (cura, correção e assistência), focaliza-se em três propósitos: curar, corrigir e cuidar, os quais são criticados pelos Estudos sobre Deficiência como orientações paternalistas e opressoras, porque deixam a pessoa com deficiência como "refém" dos especialistas e cuidadores, retirando sua agência e protagonismo.

O modelo médico, cujo foco é o déficit, vai ao encontro da manutenção do capacitismo, o qual pressupõe que as pessoas que estão fora da norma, como as pessoas com deficiência, são inferiores e incapazes em relação às pessoas sem deficiência (MUCCINI, 2017). Dentro da lógica do capacitismo, a deficiência é considerada como "um estado diminuído do ser humano" (DIAS, 2013, p. 2). Assim, o capacitismo se traduz em atitudes preconceituosas e discriminatórias. Mello (2016) sugere que se adote no Brasil, a exemplo de Portugal, capacitismo como tradução do termo em inglês ableism, diferenciando-o de disablism que significa deficientismo. Para essa autora, "ableism (ou ablism) está focalizado nas supostas capacidades das pessoas sem deficiência como referência para mostrar as supostas limitações das pessoas com deficiência" (MELLO, 2016, p. 3.267).

Ao comungar dessa diferenciação conceitual, Wolbring (2012) também não considera capacitismo como sinônimo de deficientismo, mas intimamente relacionados, pois defende que o capacitismo leva ao deficientismo. Assim, para Wolbring (2008, p. 252-53), capacitismo "é um conjunto de crenças, processos e práticas que produzem (baseado em habilidade ou valores) um entendimento de si

\footnotetext{
${ }^{3} \mathrm{Cf}$. o trecho original: "Autism is often seen as a medical problem, which means that scientists try to understand autism mainly in terms of how people's brains work".
} 
mesmo e a relação com sua autoimagem, com os outros e com o meio, incluindo como é julgado pelos outros". Esse termo é geralmente usado para descrever o tratamento negativo em relação às pessoas com deficiência, como paralelo aos termos sexismo, racismo, preconceito de idade etc. Esse autor considera o uso limitado do termo capacitismo tanto no conteúdo quanto no seu alcance. Argumenta que esse termo deve ser compreendido não apenas com relação às pessoas com deficiência, mas numa perspectiva cultural mais ampla. Entende que o capacitismo valoriza certas capacidades, o que leva à discriminação contra os "menos capazes" (WOLBRING, 2008). Dentro dessa lógica, o capacitismo seria o preconceito que produz a discriminação contra os considerados "menos capazes", seja este o negro, a mulher, o pobre, a pessoa com deficiência etc., parte da produção simbólica social. Assim, capacitismo pode ser usado com relação a todas as categorias que sofrem esse preconceito e discriminação. O capacitismo, muitas vezes, não é explícito, mas subliminar, disfarçado pelas artimanhas da produção histórica de opressão e subjugação.

Para Wolbring (2008), podem-se identificar muitas formas de capacitismo, tais como: o capacitismo biológico, baseado na estrutura; o capacitismo à base de cognição; o capacitismo com base na estrutura social, e o capacitismo inerente ao sistema econômico. O autor afirma que o capacitismo é o "ismo" mais socialmente arraigado e aceito e continua a moldar várias áreas como a segurança humana, a coesão social, as políticas sociais, as relações entre os grupos sociais, entre os indivíduos, os países, os seres-humanos e não-humanos e o meio ambiente. Declara que o capacitismo contra pessoas com deficiência reflete a preferência por habilidades normativas típicas que levam à discriminação contra as pessoas com deficiência, vistas como menos capazes e/ou incapacitadas. Esse capacitismo é fundado no modelo médico que categoriza e rejeita as "variações de ser" e a biodiversidade. (WOLBRING, 2008).

Com o intento de desconstruir o modelo médico e as concepções capacitistas, o ativismo acadêmico da área da deficiência propôs o modelo social da deficiência. Este modelo é a contribuição teórica mais difundida do campo acadêmico denominado de Estudos sobre Deficiência (Disability Studies). Este campo se consolida na década de 1970 como resultado das lutas desenvolvidas por pessoas com deficiência contra a segregação (SHAKESPEARE; WATSON, 2002), iniciado 
nos anos 60 por vários movimentos sociais como, por exemplo, o movimento dos direitos civis, o movimento de mulheres, o movimento de consumidores, e o movimento gay e lésbico nos Estados Unidos (BERGER, 2013), que culminaram numa corrente teórica no Reino Unido e nos Estados Unidos denominada de "social model of disability" (modelo social da deficiência), que teve como um dos principais precursores o sociólogo Michael Oliver (DINIZ, 2007). De acordo com Berger (2013), ao abordar os Estudos sobre Deficiência, é importante dar crédito pela sua existência e impulso conceitual ao contemporâneo movimento social pelos direitos das pessoas com deficiência de âmbito internacional, mas com significativa contribuição dos movimentos nos Estados Unidos e Grã-Bretanha.

Os Estudos sobre Deficiência, de acordo com Mello, Nuernberg e Block (2014, p. 93), "vêm despontando como um sólido campo acadêmico interdisciplinar que pretende refletir, em suas mais variadas vertentes, sobre o fenômeno da deficiência a partir do uso de métodos e técnicas de pesquisas próprios das Ciências Sociais".

Com suas tensões e divergências emanadas no próprio modelo teórico, os Estudos sobre Deficiência fomentam discussões acerca da deficiência e analisam o "ser pessoa com deficiência" e suas vidas (PFEIFFER, 2002). Derivada deste campo surge, em 1990, uma disciplina acadêmica chamada Disability Studies in Education - DSE (Estudos sobre Deficiência na Educação) como uma crítica à perspectiva biomédica da Educação Especial, trazendo a deficiência como um dos marcadores da identidade do sujeito como etnia, gênero, sexualidade, entre outros (BAGLIERI et al., 2011; GABEL; CONNOR, 2008; NUERNBERG, 2015). Tanto o modelo social da deficiência quanto os Estudos sobre Deficiência na Educação têm como princípio a justiça social e uma educação para todos. E para tanto, a eliminação das barreiras sociais é fundamental.

Como visto anteriormente, o surgimento do modelo social da deficiência principia a enfraquecer a hegemonia do modelo médico. Modelo este, que reduz a deficiência ao aspecto biológico e anatômico, compreendendo a deficiência como "tragédia pessoal" (OLIVER, 2009), uma enfermidade a ser curada ou reparada (DINIZ, 2007). Com a crítica ao modelo médico, que traz a "lesão" como desvio do que seria o normal em termos biológicos, o modelo social da deficiência faz a separação conceitual da lesão (impairment) e da deficiência (disability). A primeira 
("lesão"), relacionada à natureza física/corporal, não seria mais entendida como uma desvantagem natural, mas como uma variabilidade e expressão da natureza humana. Em relação à segunda ("deficiência"), essa não mais é compreendida como um problema individual, mas como consequência de um contexto social opressor e estigmatizante constituído com barreiras sociais, ambientais e conceituais que tornam a característica atípica da pessoa uma desvantagem (FELDMAN, 2013). Tornando, assim, a deficiência um conceito amplo e relacional, um fenômeno sociológico (DINIZ, 2003). Entende-se que a deficiência, como toda e qualquer forma de desvantagem, é resultado da relação/interação do corpo com lesão (limitação funcional) e a sociedade/ambiente (DINIZ, 2003; GABEL; CONNOR, 2008; OLIVER, 2009).

Para o modelo social da deficiência, o aspecto do déficit/lesão deve ser concebido como uma forma natural de variação humana, parte da diversidade humana e não como uma característica indesejada que deve ser curada ou corrigida (GABEL; CONNOR, 2008; GILSON; DEPOY, 2000). Esse modelo apresenta dois momentos distintos em sua consolidação. A primeira geração do modelo social surgiu a partir da UPIAS (Union of the Physically Impaired Against Segregation) e deu início ao movimento. Esta, formada por pessoas com deficiência física do sexo masculino, entende a discriminação pela deficiência como opressora e a opressão social como a principal barreira que impede a independência da pessoa com deficiência, fundamental para a vida humana. Como princípio, esse modelo buscava a eliminação da opressão e a inserção no mercado de trabalho (DINIZ, 2007). A compreensão de que os problemas relacionados à deficiência estão imbricados pela estrutura social e não com a estrutura funcional do corpo permitiu às pessoas com deficiência uma leitura renovada dos seus corpos e de suas posições sociais (MARTINS et al., 2012). A segunda geração, constituída na sua maioria por mulheres com deficiência feministas e cuidadoras, opunha-se à defesa dos membros da primeira geração desse modelo com o entendimento de que, mesmo retiradas as barreiras físicas, a pessoa com deficiência pode necessitar de auxílio na condução da sua vida, trazendo com isso a experiência da dor, a ideia da interdependência como condição humana e o cuidado como demanda de justiça social (DINIZ, 2007; GESSER; NUERNBERG; TONELI, 2012). Assim, o modelo social da deficiência recoloca a pessoa com deficiência na categoria de "humano", 
destruindo com subcategorias sociais construídas de "menos humanos" e "mais humanos". E nessa categoria a interdependência e o cuidado são compreendidos como naturais, ou seja, a interdependência podendo ser vivida por pessoas com ou sem deficiência e o cuidado podendo ser necessitado e oferecido também por ambas. Isso faz com que o olhar esteja voltado para a vivência de cada pessoa, considerando a deficiência num contexto integrado com outros marcadores sociais das diferenças.

Ao considerar esses aspectos, o autismo, a partir da ótica do modelo social, é compreendido como uma variação humana, como uma diferença que constitui a pessoa tanto quanto outras, como raça/etnia, classe social e orientação sexual. A segunda geração do modelo social aborda elementos que auxiliam na compreensão dessa abordagem. Com base nesta perspectiva, a diferença neurológica é caracterizada como lesão e as condições normocêntricas que colocam a pessoa com autismo socialmente em desvantagem são caracterizadas como produtoras da experiência de deficiência. A diversidade autista nos remete a pensar que a relação lesão/deficiência é mais complexa que outras deficiências como a física, por exemplo, na qual ao eliminar as barreiras arquitetônicas, atitudinais, entre outras, a pessoa fica em equidade de condições de acesso e também em equidade para a execução de determinada tarefa. No caso do autismo, essa relação se torna mais complexa, a equidade não se dá de forma simples. Sinclair (2012, p.1. Tradução nossa) afirma que o autismo "é impregnante; colore toda a experiência, cada sensação, percepção, pensamento, emoção e encontra cada aspecto da existência", não sendo "possível separar o autismo da pessoa - e se fosse possível separar, a pessoa que você deixaria não seria a mesma pessoa com quem você começou"4.

A despeito da diversidade autista, o fato de eliminarmos as barreiras externas nem sempre oportuniza à pessoa com autismo uma condição de equidade significativa. A segunda geração do modelo social previu isso, considerando aspectos identitários e funcionais que independem das barreiras físicas, comunicacionais, pedagógicas etc. A partir da premissa feminista da natureza identitária do corpo, as autoras feministas superaram a dicotomia impedimento

4 Cf. o trecho original: "It is pervasive; it colors every experience, every sensation, perception, thought, emotion, and encounter, every aspect of existence. It is not possible to separate the autism from the person - and if it were possible, the person you'd have left would not be the same person you started with". 
versus barreiras sociais. Assim, no caso do autismo, não se trata apenas de uma condição diversa quando comparada com a hegemônica. A "lesão" causa diversos problemas sensoriais, o que faz com que mesmo um ambiente mais acolhedor $\mathrm{e}$ livre de barreiras muitas vezes não seja capaz de modificar a relação sujeito/ ambiente. Campos et al. (2017, p.111) afirmam que "o autismo não se esgota na sua condição orgânica, mas é objeto de diferentes áreas do conhecimento que apontam a diferença transformada em desigualdade como construção social". Assim, o autismo, como outras deficiências, é produzido socialmente, levando-se em conta sempre um padrão dominante de normalidade.

Com base nos Estudos sobre Deficiência (Disability Studies) e no modelo social da deficiência, um grupo - formado principalmente por ativistas com autismo combate o olhar medicalizante sobre o autismo. Esse grupo constitui o movimento internacional chamado "neurodiversidade", que tem como lema "nada sobre nós sem nós" e entende o autismo como parte da variação humana, contrapondo-se a padrões de normalidade cerebral e à obrigação de ser "curado" (ORTEGA, 2009).

Segundo Donvan e Zucker (2017), o termo "neurodiversidade" é creditado a Jim Sinclair, socióloga australiana com autismo que em 1990 usou o termo em sua tese. Sinclair, em uma palestra em Toronto, argumentou que era um erro dos pais e mães acreditarem que o fato de o filho ter autismo era um "golpe terrível do destino" e, com a frase "Não chore por nós", dizia que não havia necessidade de pranto. Assim, Sinclair se contrapôs à premissa de que o autismo era uma maldição, um parasita, um inimigo, ideia essa que predominava na opinião social, inclusive pelo movimento de pais que, apesar de dedicados a melhorar o mundo de seus filhos, traziam um discurso imbuído de tristeza e que caracterizava o autismo como algo errado (DONVAN; ZUCKER, 2017, p. 514-515). Com isso, inicia, em 1993, o movimento da Neurodiversidade, corroborando com a compreensão do modelo social.

Zaks (2015) afirma que os adeptos da neurodiversidade propõem que, em vez de ver o autismo como "um erro da natureza, um quebra-cabeça para ser resolvido e eliminado com técnicas como testes pré-natais e abortos seletivos, a sociedade deve considerá-lo como uma parte valiosa do legado genético da humanidade"5 ( $p$.

\footnotetext{
${ }^{5}$ Cf. o trecho original: "an error of nature - a puzzle to be solved and eliminated with techniques like prenatal
} testing and selective abortion - society should regard it as a valuable part of humanity's genetic legacy". 
478. Tradução nossa). O termo neurodiversidade busca retratar a constituição neurológica diversa do ser humano, neurotípicos (os não-autistas) e neuroatípicos (os autistas), entendendo o segundo como uma diferença humana que deve ser respeitada como outras diferenças (ORTEGA, 2009). Isso não implica negar, por exemplo, maior dificuldade de pessoas com autismo em relação ao sono, à alimentação (hiperseletividade alimentar) e aos transtornos sensoriais, como apontado em alguns estudos, mas concebê-los numa perspectiva diferenciada. Isso significa, que dificuldades apresentadas não fazem parte de um modelo deficitário ou um problema, porque foge ao modo de funcionar padrão. É preciso a oferta de recursos sociais e de saúde em prol da promoção da qualidade de vida não apenas do ponto de vista biomédico, mas também em relação às mudanças ambientais necessárias para garantir a convivência e a inclusão plena das pessoas com autismo ${ }^{6}$.

De acordo com Hughes (2015), os defensores da neurodiversidade baseiamse em um modelo de direitos da deficiência com o fundamento de que todas as pessoas devem ser aceitas e apoiadas nas suas diferentes formas de pensar e ser. A aceitação do autismo, segundo Lydia Brown, ativista citada por Silberman (2012), não significa negar a deficiência.

O olhar sob a ótica da neurodiversidade possibilita atitudes de inclusão social, aceitação e apoio, descartando a ideia de que ser pessoa com deficiência, com autismo de "baixo funcionamento" etc., é menos desejável do que "normal" ou com modo de vida "de alta funcionalidade" (HUGHES, 2015).

Walker (2014, s/n. Tradução nossa) argumenta que "neurotípico é o oposto do neurodivergente, não o oposto de autista" e que "usar neurotípico para significar não-autista é como usar 'branco' para significar 'não preto'”7. Nesse sentido, como oposto de autista, Hughes (2015, p. 13) traz o termo "allistic" (que significa nãoautista); termo esse inventado pelos próprios autistas.

\footnotetext{
6 Um exemplo são as sessões de cinema conduzidas no Brasil com o apoio de ONGs que consideram as dificuldades sensoriais das pessoas com autismo e modificam a luminosidade das sessões, retiram os trailers e acolhem a possibilidade de maior liberdade aos espectadores com autismo durante o filme.

7 Cf. o trecho original: "Neurotypical is the opposite of neurodivergent, not the opposite of autistic". "Using neurotypical to mean non-autistic is like using 'white' to mean 'not black'."
} 
Jim Sinclair criou em 1994 uma organização online denominada ANI - Autism Network International -, tendo como um dos propósitos a discussão das ideias da neurodiversidade, mas não conseguiu com isso sua popularização (DONVAN; ZUCKER, 2017). Em força contrária, surgem organizações como Cure Autism Now, Defeat Autism Now, dentre outras. A entidade maior e mais importante, de acordo com Donvan e Zucker (2017, p.515), foi Autism Speaks, criada em 2000, e lançada num site com a declaração: "Essa doença arrebatou os nossos filhos. É tempo de recuperá-los". Forças em disputas foram construindo o universo sócio-político do autismo. Em meados de 2007, Ari Ne'eman, estudante secundarista com autismo, fundou a ASAN - Autistic Self-Advocacy Network, com o lema "Nada sobre nós sem nós", com o propósito de garantir que os autistas fossem ouvidos nos debates sobre políticas e espaços de poder (DONVAN; ZUCKER, 2017, p. 517), estendendo essa participação para o processo de fazer a própria ciência (ZAKS, 2015). AASAN, como mais um grupo de interação da neurodiversidade, opunha-se às ideias e abordagens do Autism Speak (DONVAN; ZUCKER, 2017). Esse grupo e outros defensores da neurodiversidade temem pesquisas genéticas insensíveis e que procurem a identificação diagnóstica do TEA no período pré-natal, com receio de que isso possibilite a implantação de políticas eugênicas em relação ao autismo (KRCEK, 2013. Da mesma forma que historicamente ocorreu um movimento eugênico em relação às pessoas com deficiência, cujo princípio era a melhoria da raça humana por meio da eliminação dos "considerados indesejáveis" e como consequência, dentre outros, a restrição de casamento entre "portadores de desabilidades hereditárias" (ALFONSO-GOLDFARB; FERRAZ, 2013) e a esterilização de pessoas com deficiência (KRCEK, 2013).

Ortega (2008) traz a afirmação de Singer (1999), na qual considera que o movimento da neurodiversidade foi possível, principalmente, pela influência do feminismo, dando autoconfiança às mães para contraporem a culpabilização direcionada a elas pelo modelo psicanalítico; o crescimento de grupos de apoio de atendimento aos pacientes e a diminuição da autoridade dos médicos; bem como pelo aumento de movimentos políticos, de autodefesa e autoadvocacia de pessoas com deficiência.

Krcek (2013) relata que, mesmo existindo grupos como a ASAN, de autodefesa autista, não é consensual sua representatividade; há autistas como 
Temple Grandin, que, apesar de reconhecer a discriminação da sociedade e o autismo como outra maneira de pensar, não se identifica fortemente com o movimento da neurodiversidade e não é totalmente contrária ao conceito do autismo como deficiência e à proposta de cura.

No artigo de Savarese et al. (2010), resultado de uma mesa redonda de pais e irmãos sobre neurodiversidade e cuidados, há o depoimento do pai de um jovem com autismo (San), que afirma ter uma prática voltada para a neurodiversidade: o pai relata que San tem dificuldades com multidões, que não gosta de coisas novas e late quando algo não é bom ou bate a cabeça quando chateado, mas aceita tudo isso porque este é o San e não tenta (e não pode) mudá-lo; aprendeu a ver como diferença os comportamentos compreendidos como problemáticos, sendo seu desejo que "ele se sinta confortável em sua própria pele, com quem ele é: um jovem incrível com um senso de humor mordaz e um entusiasmo pela vida"8 (p. 3. Tradução nossa).

Dentro de uma lógica muito parecida com a dos defensores da cultura surda, pessoas com autismo ativistas e defensoras da neurodiversidade encaram o autismo como uma "cultura", uma "questão identitária" (ORTEGA, 2008; SINCLAIR, 2012). Para Ortega (2008, p. 487), "os movimentos da neurodiversidade, especificamente a cultura autista, constituem exemplos de formas de subjetivação cerebrais, de formação de neuroidentidades e tipos de sociabilidade e comunidade, as neurossociabilidades, tomando o cérebro como referência".

O movimento de/para pessoas com autismo que tem como referência o modelo médico faz críticas à perspectiva da neurodiversidade. Os integrantes desse movimento argumentam que a neurodiversidade tem na sua totalidade membros autistas de alto funcionamento e é somente este grupo que é considerado, bem como os defensores não são favoráveis em relação a pesquisas na área e são imparciais para encontrar tratamento para pessoas com autismo. O movimento da neurodiversidade se defende argumentando que em ambos os movimentos - o da neurodiversidade e o de pró-cura para o autismo - há pessoas com autismo de alto funcionamento. Argumentam ainda que, no movimento da neurodiversidade, há também pessoas com autismo não-verbais, como Amanda Baggs. Em relação às

\footnotetext{
8 Cf. o original: "I want him to feel comfortable in his own skin, with who he is: a terrific young man with a wicked sense of humor and a zest for life".
} 
pesquisas, o movimento declara que dá valor à pesquisa e à descoberta de novos tratamentos, mas quer cautela nas pesquisas genéticas, bem como se preocupa com a garantia do direito da pessoa com autismo para decidir sobre a melhor abordagem ou contra o tratamento (KRCEK, 2013).

De acordo com Ortega (2008), o Brasil, com o movimento Orgulho Autista Brasil, faz parte da rede de países que comemora a neurodiversidade e tem uma perspectiva contrária às associações de pais e profissionais que buscam a cura para o autismo, como a AMA (Associação de Amigos de Autistas) e a AUMA (Associação de Amigos da Criança Autista). O termo "orgulho" autista é usado tanto para celebrar as "diferenças" no autismo, como para dar visibilidade para as ações institucionais em prol da normatização e integração da pessoa com autismo.

Há divergências entre ativistas autistas e organizações de pais no que se refere a buscar a causa e a cura do autismo. Hughes (2015, p. 131) cita um estudo de pesquisa de Kapp, Gillespie-Lynch, Sherman e Hutman (2013) em que descobriram que a maioria dos inquiridos autistas estava desinteressada na questão da causa do autismo, diferentemente da maioria dos pais, os quais tinham como prioridade encontrar uma causa para o autismo. Essa divergência toma corpo em um embate político entre os ativistas do movimento autista e os grupos pró-cura e, segundo Ortega (2008),

um dos pontos mais conflitantes diz respeito à terapia cognitiva $A B A$ (Análise Comportamental Aplicada - Applied Behavior Analysis), que para muitos pais constitui a única terapia que permite às crianças autistas realizarem algum progresso no estabelecimento de contato visual e em certas tarefas cognitivas. Para os ativistas autistas, a terapia reprime a forma de expressão natural dos autistas (Dawson 2004). A questão é acirradamente debatida no mundo anglo-saxão, já que muitos pais estão lutando na Justiça para conseguir que governos e companhias de seguros de saúde paguem pela terapia, cujo custo é muito elevado. (p. 481).

Apesar das disputas e divergências em relação à compreensão do autismo, há pontos de concordância entre os pais e defensores da visão médica com os defensores da neurodiversidade. Um ponto de convergência é o entendimento de que o autismo não é uma entidade unificada, é um conjunto de condições que diferem de um indivíduo para outro, produzindo comportamentos e necessidades que são distintos e se manifestam de diferentes formas. Concordam também que a 
variedade que compõe o espectro autista requer apoio e cuidados dos pais, dos educadores e da comunidade em geral (ZAKS, 2015).

Sobre o cuidado, Kittay (2011) aborda-o como virtude e reconhece a dependência como condição humana e não restrita à deficiência. O cuidado passa a ser um elemento central nas relações entre pessoas com e sem deficiência e como algo que deve transcender a dimensão do privado. Para a autora, as pessoas com deficiência sofrem discriminação, e buscar uma ética do cuidado é contemplar a dignidade, o bem-estar e oferecer um recurso de reparação moral. A autora também considera importante romper com a ideia do cuidado e da dependência como negativos, bem como com a ideia da pessoa cuidada como coitada, digna de pena e sem direito a voz.

Para Kittay (2011), nas teorias dominantes de justiça, a dignidade é acoplada com a capacidade de autonomia e bem-estar, mas quando a pessoa depende de outra para seu autocuidado, como é o caso de muitas das pessoas com deficiência, sua dignidade parece estar ameaçada. A autora defende que o cuidado "não seria visto como sinal de dependência, mas como uma prótese que permite a pessoa ser independente" (KITTAY, 2011, p. 50. Tradução nossa) ${ }^{9}$. Traz a afirmação de Judy Heumann, uma das fundadoras do movimento Vida Independente, que entende que a independência não significa fazer as coisas sozinho, mas ser capaz de tomar decisões de maneira independente. Reconhece a dependência como característica de toda a vida humana, em que as pessoas se deslocam dentro e fora das relações de dependência em diferentes momentos da vida e de suas condições de saúde e funcionamento. Nesse sentido, é fundamental estabelecer relações que são realmente atenciosas e respeitosas tanto para quem é cuidado quanto para o cuidador (KITTAY, 2011).

Kittay (2011) relata que a ética baseada na assistência tem sido objeto de crítica e torna-se inadequada para uma ética da inclusão. A autora argumenta que, se considerarmos todas as pessoas que se deslocam dentro e fora das relações de dependência em diversos estágios da vida e condições de saúde e funcionamento, o fato de as pessoas com deficiência necessitarem de assistência de um cuidador não é exceção, ou um caso especial, mas sim uma possibilidade inerente ao ser

\footnotetext{
${ }^{9}$ Cf. o trecho original: "is viewed not as a sign of dependence but as a sort of prosthesis that permits one to be
} independent". 
humano. As relações estabelecidas no contexto de cuidado são desiguais, mas é importante, ao invés de estabelecer uma relação de paternalismo, construir relações de cooperativismo, respeito, atenção para aqueles que dependem de cuidado em momentos de necessidades. A ética do cuidado se estende para além da esfera privada das relações íntimas. Uma ética pública do cuidado é defendida por Kittay (2011, p. 56. Tradução nossa $)^{10}$, que tem como base "a ideia de que estamos todos encaixados nas dependências aninhadas".

Zaks (2015) afirma que uma crescente aliança entre pessoas com autismo, pais e educadores defensores da neurodiversidade possibilitou inovações para um mundo aberto à diversidade autista. Exemplo dessas inovações seriam as escolas inclusivas com, por exemplo, espaços silenciosos designados para o estudante autista evitar uma crise devido à sobrecarga sensorial.

Ao corroborar essa ideia de uma escola inclusiva, o modelo social da deficiência, a partir de um processo bilateral, retira a pessoa como centro e estabelece uma relação em que ambos (sujeito e sociedade) são partícipes na construção e efetivação do processo inclusivo (Carvalho e Marquezan, 2003). Isso implica garantir as condições de participação do estudante com autismo conforme seu potencial de desenvolvimento, envolvendo recursos como imagens, histórias sociais e de ensino apoiado que proporcione equidade no acesso ao conhecimento, dentro de sua Zona de Desenvolvimento Proximal (VYGOTSKY, 1998). Na área do trabalho, a neurodiversidade está sendo incorporada por empresas, a exemplo da Dinamarca, que empregam pessoas com autismo e que, ao selecioná-las, consideram suas especificidades e a escolha é feita de forma que os candidatos simplesmente mostrem suas habilidades em vez de precisar explicá-las (ZAKS, 2015).

Woods (2017) traz o argumento de Levitt de que o modelo social da deficiência precisa ser revigorado, devendo ser adaptado para diferentes países. Além disso, destaca que o modelo social não é implementado para pessoas neurodivergentes como os autistas. Defende que, "do ponto de vista da neurodivergência, o modelo social deve ser visto como sendo complementar de outros modelos de deficiência", sendo que "não é o único modelo de deficiência e o

\footnotetext{
${ }^{10} \mathrm{Cf}$. o trecho original: "the idea that we are all embedded in nested dependencies".
} 
modelo possui numerosas limitações", considerando que "o modelo social nem sempre explica como a deficiência é experimentada" (WOODS, 2017, p. 7-8). Apesar das limitações, o autor compreende que o modelo social pode, sim, ser revigorado para o autismo e sua implementação dar-se-á removendo barreiras sociais: alterando as atitudes das pessoas neurotípicas sobre o autismo, garantindo a linguagem positiva do autismo e não como déficit e desordem, além de remover a categorização (subcategorias e subníveis); fazendo ajustes nas instituições de neurotípicos, o que pode ser feito mudando a lei ou implementando plenamente a legislação existente. O autor acredita que "quando implementado, o modelo social é uma poderosa ferramenta para alcançar a emancipação de todas as pessoas com deficiência"11 (WOODS, 2017, p. 9. Tradução nossa).

Ter o modelo social da deficiência como base para a compreensão do autismo é entender essa condição para além do aspecto biológico, como uma das características da pessoa, dentre tantas outras tão importantes. É não ignorar a constituição da pessoa, incluindo o autismo nesse contexto, mas não este como determinante. É considerar a deficientização social a que estão submetidas as pessoas com deficiência e sua condição de vulnerabilidade, buscando a remoção das barreiras e possibilitando a sua condição de participação e emancipação.

\section{CONSIDERAÇÕES FINAIS}

O autismo pode ser compreendido de várias formas. Esse artigo teve como foco principal apresentar o modelo social da deficiência e suas implicações na compreensão do autismo. O modelo social da deficiência traz elementos para que possam ser mudadas as práticas homogeneizantes e normalizadoras na atuação profissional com as pessoas com autismo. Além disso, o modelo em destaque serviu como base teórica para a Convenção Internacional sobre os Direitos das Pessoas com Deficiência e seu Protocolo Facultativo (BRASIL, 2007), que foi incorporada à legislação brasileira (ratificada com força de Emenda Constitucional por meio do Decreto Legislativo n¹86/2008 e do Decreto 6.949/2009). Essa Convenção deve

\footnotetext{
${ }^{11}$ Cf. o trecho original: "When implemented, the social model is a powerful tool for achieving emancipation of all disabled people".
} 
orientar todas as práticas voltadas às pessoas com deficiência, inclusive às pessoas com autismo.

Para a compreensão da deficiência, todos os aspectos são fundamentais, tanto os biológicos e funcionais, quanto os sociais, psicológicos, econômicos etc., ou seja, todos os aspectos que constituem a existência da pessoa na relação com o meio. É importante termos claro que a maneira como concebemos a deficiência e, neste caso, o autismo, direciona nossas ações. Não existe um único modelo que seja abrangente a ponto de absorver toda a complexidade da pessoa. Nesse sentido, é importante o não enquadramento da pessoa ao modelo, mas ter como base modelos que possam contribuir na compreensão da pessoa com deficiência de forma integral e relacional.

O modelo social da deficiência pode contribuir para diversas áreas do conhecimento, uma vez que esse modelo desloca o olhar direcionado à deficiência para a pessoa na relação com o contexto social e político. Algumas contribuições importantes devem ser consideradas e incorporadas no trabalho com as pessoas com deficiência, como o foco na pessoa e não no "déficit"; a proposição de eliminação das barreiras, das práticas opressoras e das atitudes capacitistas; o cuidado como componente de todas as práticas e não somente o cuidado no âmbito privado; a interdependência como algo natural da existência humana e não restrita à deficiência. Pela complexidade em que se apresenta o Transtorno do Espectro Autista, esse modelo não consegue contemplar todas as suas especificidades, mas nem por isso deixa de trazer grandes contribuições à sua compreensão e às práticas voltadas a esse grupo.

Conclui-se que conceber o autismo a partir do modelo social da deficiência é entendê-lo como uma diversidade biológica que faz parte da variação humana. Essa compreensão aponta para a necessidade de que as pessoas com autismo sejam acolhidas e ouvidas nos diversos contextos sociais, e que possam participar dos processos de construção dos espaços e das políticas públicas. Além disso, destacase que essa população deve poder ter acesso ao conhecimento, considerando suas especificidades na maneira de aprender e de estar no mundo. Para isso, faz-se necessário romper com os padrões normocêntricos de ser e estar no mundo, os quais produzem como efeito violências e exclusão, e buscar a construção de relações sociais pautadas no acolhimento das diferenças. Assim, considera-se que 
compreender o autismo a partir do modelo social da deficiência contribui para as práticas inclusivas voltadas ao atendimento das pessoas que vivenciam essa condição.

\section{REFERÊNCIAS}

APA - AMERICAN PSYCHIATRIC ASSOCIATION. Manual de Transtornos Mentais DSM-5. Porto Alegre: Artmed, v. 1, 2014. Disponível em: <http://c026204.cdn.sapo.io/1/ c026204/cld-file/1426522730/6d77c9965e17b15/b37dfc58aad8cd477904b9bb2ba8a75b/ obaudoeducador/2015/DSM V.pdf>. Acesso em: 27 mai. 2017.

ARAÚJO, A. C.; NETO, F. L. A Nova Classificação Americana Para os Transtornos Mentais o DSM-5. Revista Brasileira de Terapia Comportamental e Cognitiva. São Paulo, v. XVI, n. 1, p. 67-82, 2014. Disponível em: <http://pepsic.bvsalud.org/pdf/rbtcc/v16n1/ v16n1a07.pdf>. Acesso em: 27 mai. 2017.

BAGLIERI, S. et al. Disability Studies in Education: The Need for a Plurality of Perspectives on Disability. Remedial and Special Education, [s. I.], v. 32, n. 4, p. 267-278, 2011. Disponível em: <http://rse.sagepub.com/cgi/doi/10.1177/0741932510362200>. Acesso em: 27 mai. 2017.

BERGER, R. J. Introducing Disability Studies. Estados Unidos da América: Lynne Rienner Publisher, 2013.

BRASIL. Convenção Internacional sobre os Direitos das Pessoas com Deficiência: Protocolo Facultativo sobre os Direitos das Pessoas com Deficiência. Brasília: SEDH, CORDE, 2007. Disponível em: <http://portal.mec.gov.br/index.php? option=com_docman\&view=download\&alias=424-cartilha-c\&category_slug=documentospdf\&Itemid= $\overline{3} 0192>$. Acesso em: 27 mai. 2017.

BRASIL. LEI No 12.764 de 27 de dezembro de 2012. 2012. Disponível em: <http:// www.planalto.gov.br/ccivil_03/_ato2011-2014/2012/lei//12764.htm>. Acesso em: 28 mai. 2017.

CAMPOS, K. P. B. et al. João em situação de autismo: o que fazem e dizem as crianças na Educação Infantil. Revista Educação, Artes e Inclusão. Florianópolis, v. 13, n. 2, p.1101352017. Disponível em: <http://www.revistas.udesc.br/index.php/arteinclusao/article/view/ 8554>. Acesso em: 14 abr. 2018.

CARVALHO, R. C.; MARQUEZAN, R. Representações sociais sobre a deficiência em documentos oficiais. Revista Educação. Santa Maria/RS, v. 28, n. 2, p. 1-5, jul/dez., 2003. Disponível em: <https://periodicos.ufsm.br/reveducacao/article/view/4169/2505>. Acesso em: 18 abr. 2018.

DIAS, A. Por uma genealogia do capacitismo: da eugenia estatal à narrativa capacitista social. Anais do II Simpósio Internacional de Estudos sobre Deficiência. São Paulo, p. 5-14, 2013.

DINIZ, D. Modelo Social da Deficiência: A Crítica Feminista. SérieAnis. Brasília, v. 28, p. 18, 2003. Disponível em: <http://repositorio.unb.br/bitstream/10482/15250/1/ ARTIGO_ModeloSocialDeficiencia.pdf>. Acesso em: 27 mai. 2017.

DINIZ, D. O Que é Deficiência. São Paulo: Editora Brasiliense; 2007. 96 pp. (Coleção Primeiros Passos, 324) 
DONVAN, J.; ZUCKER, C. Outra sintonia: a história do autismo. 1a ed. São Paulo: Companhia das Letras (Original In a Different Key: The Story of Autism: Tradução Luiz A. de Araújo), 2017. 664 p.

FELDMAN, C. Relatos sobre autismo: um estudo sobre narrativas em primeira pessoa. 2013. Rio de Janeiro, Universidade do Estado do Rio de Janeiro, 2013. Disponível em: $<$ http://www.bdtd.uerj.br/tde_busca/arquivo.php?codArquivo=6315>. Acesso em: 27 mai. 2016. Acesso em: 05 jun. $2 \overline{0} 17$.

GABEL, S. L.; CONNOR, D. Theorizing Disability Implications and Applications for Social Justice in Education Disability Studies in Education. International Journal of Inclusive Education. Reino Unido, 2008. Disponível em: <https://www.researchgate.net/publication/ 244988407_Theorizing_Disability_Implications_and_Applications_for_Social_Justice_in_Edu cation_Disability_Studies_in_Education>

GESSER, M.; NUERNBERG, A. H.; TONELI, M. J. F. A contribuição do modelo social da deficiência à psicologia social. Psicologia \& Sociedade. Belo Horizonte, v. 24, n. 3, p. 557566,2012 . Disponível em: <http://www.scielo.br/scielo.php? script=sci_arttext\&pid=S0102-71822012000300009\&lng=pt\&tlng=pt>. Acesso em: 27 mai. 2017.

GIL, A. C. Como Elaborar Projetos de Pesquisa. 4. ed. São Paulo: Editora Atlas S. A., 2002.

GIL, A. C. Métodos e Técnicas de Pesquisa Social. 6ª ed. São Paulo: Editora Atlas S. A., 2008.

GILSON, S. F.; DEPOY, E. Multiculturalism and Disability: A critical perspective. Disability \& Society. Reino Unido, v. 15, n. 2, p. 207-218, 2000. Disponível em: <http:// www.tandfonline.com/doi/abs/10.1080/09687590025630>. Acesso em: 29 mai. 2017.

HUGHES, J. M. F. Changing Conversations Around Autism: A Critical, Action Implicative Discourse Analysis of U.S. Neurodiversity Advocacy Online. University of Colorado, Colorado, 2015. Disponível em: <htt://scholar.colorado.edu/comm_gradetds/52>. Acesso em: 31 out. 2017.

KAPP, S. K. et al. Deficit, difference, or both? Autism and neurodiversity. Developmental Psychology. Washington, v. 49, n. 1, p. 59-71, 2013. Disponível em: <http://doi.apa.org/ getdoi.cfm?doi=10.1037/a0028353>. Acesso em: 10 mai. 2017.

KITTAY, E. F. The Ethics of Care, Dependency, and Disability. Ratio Juris, v. 24, n. 1, p. 4958, 2011. Disponível em: <http://evafederkittay.com/wp-content/uploads/2015/01/The-ethicsof-care.pdf>. Acesso em: 19 set. 2017.

KRCEK, Taylor E. Deconstructing Disability and Neurodiversity: Controversial Issues for Autism and Implications for Social Work. Journal of Progressive Human Services. Reino Unido, v. 24, n. 1, p. 4-22, 2013. Disponível em: < https://www.tandfonline.com/doi/abs/ 10.1080/10428232.2013.740406>. Acesso em: 18 out. 2017.

MARTINS, B. S. et al. A emancipação dos estudos da deficiência. Revista Crítica de Ciências Sociais, n. 98, p. 45-64, 2012. Disponível em: <https://journals.openedition.org/ rccs/5014>. Acesso em: 28 set. 2017.

MELLO, A. G. de. Deficiência, incapacidade e vulnerabilidade: do capacitismo ou a preeminência capacitista e biomédica do Comitê de Ética em Pesquisa da UFSC. Ciência \& Saúde Coletiva, v. 21, n. 10, p. 3265-3276, 2016. Disponível em: <http://www.scielo.br/ scielo.php?script=sci_arttext\&pid=S1413-81232016001003265\&lng=pt\&tlng=pt $>$. Acesso 
em: 19 set. 2017.

MELLO, A. G. de; NUERNBERG, A. H.; BLOCK, P. Não é o corpo que nos discapacita, mas sim a sociedade: a interdisciplinaridade e o surgimento dos estudos sobre deficiência no Brasil e no mundo. In: SCHIMANSCKI, E.; CAVALCANTE, F. G (org). Pesquisa e extensão: experiências e perspectivas interdisciplinares. Ponta Grossa: Editora da UEPG, 2014. $264 \mathrm{p}$.

MUCCINI, P. Estudantes com surdocegueira na Universidade: mapeando barreiras e facilitadores que perpassam o processo de inclusão acadêmica. 2017. Universidade Federal de Santa Catarina, Florianópolis, 2017. Disponível em: <www.bu.ufsc.br>. Acesso em: 4 mar. 2018.

Nova Classificação de Doenças, CID - 11, unifica Transtorno do Espectro do Autismo: 6A02. Tismoo, 2018. Disponível em: <http://tismoo.us/saude/diagnostico/nova-classificacao-dedoencas-cid-11-unifica-transtorno-do-espectro-do-autismo-6a02/>. Acesso em: 20 set. 2018.

NUERNBERG, A. H. Os Estudos sobre Deficiência na Educação. Educação \& Sociedade, v. 36, n. 131 , p. 555-558, 2015. Disponível em: <http://www.scielo.br/scielo.php? script=sci_arttext\&pid=S0101-73302015000200555\&lng=pt\&tlng=pt $>$. Acesso em: 28 mai. 2017.

O'DELL, L. et al. Critical autism studies: exploring epistemic dialogues and intersections, challenging dominant understandings of autism. Disability \& Society, v. 31, n. 2, p. 166179 , 2016. Disponível em: <https://www.tandfonline.com/doi/abs/ 10.1080/09687599.2016.1164026?journalCode=cdso20>. Acesso em: 20 out. 2017

OLIVER, M. Understanding disability: from theory to practice. $2^{a}$ ed. United Kingdom: Macmillan Education UK, 2009.

ORTEGA, F. Deficiência, autismo e neurodiversidade. Ciência \& Saúde Coletiva, v. 14, n. 1, p. 67-77, 2009. Disponível em: <http://www.scielo.br/scielo.php? script=sci_arttext\&pid=S1413-81232009000100012\&Ing=pt\&tlng=pt>. Acesso em: 24 out. 2017.

ORTEGA, F. O sujeito cerebral e o movimento da neurodiversidade. Mana, v. 14, n. 2, p. 477-509, 2008. Disponível em: <http://www.scielo.br/scielo.php? script=sci_arttext\&pid=S0104-93132008000200008\&lng=pt\&tlng=pt $>$. Acesso em: 18 out. 2017.

PEREIRA, A. M. B. A. Viagem ao Interior da Sombra: Deficiência, Doença Crônica e Invisibilidade numa Sociedade Capacitista. 2008. Universidade de Coimbra, Portugal, 2008.

PFEIFFER, D. The Philosophical Foundations of Disability Studies. Ohio State University Libraries, v. 22, 2002. Disponível em: <http://dsq-sds.org/article/view/341/429>. Acesso em: 29 mai. 2017.

SAVARESE, R. J. et al. Parent \& Sibling Roundtable: Neurodiversity and Caregiving. Ohio State University Libraries, v. 30, 2010. Disponível em: <http://dsq-sds.org/article/view/ 1061/1236>. Acesso em: 18 out. 2017.

SHAKESPEARE, T.; WATSON, N. The social model of disability: an outdated ideology? Journal Research in Social Science and Disability, v. 2, p. 9-28, 2002. Disponível em: <http://www.um.es/discatif/PROYECTO_DISCATIF/Textos_discapacidad/ 00_Shakespeare2.pdf>. Acesso em: 16 jun. 2017.

SILBERMAN, S. Autism awareness is not enough: Here's how to change the world. In: Loud hands: Autistic people, speaking. Washington: The Autistic Press, p. 358-386, 2012. 
SINCLAIR, J. Don't Mourn For Us. Autism Network International, v. 1, n. 1, 2012.

SINGER, J. Why can't you be normal for once in your life?' From a 'problem with no name' to the emergence of a new category of difference. In: Disability discourse. Buckingham, Philadelphia: Open University Press, p. 59-67, 1999.

VYGOTSKY, L. S. A formação social da mente: o desenvolvimento dos processos psicológicos superiores. 6. ed. São Paulo: Editora Martins Fontes, 1998.

WALKER, N. Neurodiversity: Some Basic Terms \& Definitions. 2014. Disponível em: $<$ http://neurocosmopolitanism.com/neurodiversity-some-basic-terms-definitions/>. Acesso em: 8 nov. 2017.

WOLBRING, G. Expanding Ableism: Taking down the Ghettoization of Impact of Disability Studies Scholars. Societies, 2 (3), p. 75-83, 2012. Disponível em: <https:// pdfs.semanticscholar.org/1e64/78147e301f9875a144ab58d4fed09a502c5a.pdf>. Acesso em: 15 jul. 2017.

WOLBRING, G. The Politics of Ableism. Development, v. 51, n. 2, p. 252-258, june, 2008. Disponível em: <http://www.palgrave-journals.com/doifinder/10.1057/dev.2008.17>. Acesso em: 19 set. 2017.

WOODS, R. Exploring how the social model of disability can be re-invigorated for autism: in response to Jonathan Levitt. Disability \& Society, p. 1-6, 2017. Disponível em: <https:// www.tandfonline.com/doi/full/10.1080/09687599.2017.1328157>. Acesso em: 21 jun. 2017.

WORLD HEALTH ORGANIZATION. ICD - 11 International Classification of Diseases 11th Revision: The global standard for diagnostic health information. 2018. Disponível em: $<$ https://icd.who.int/>. Acesso em: 10 jul. 2018.

ZAKS, Z. Building the Enterprise: Designs for a Neurodiverse World. In: NeuroTribes: The Legacy of Autism and the Future of Neurodiversity. New York: Avery Publishing, p. 286292, 2015.

Recebido em: 10-05-2018

Aprovado em: 18-03-2019 